\title{
ENVOLVIMENTO RENAL NA ASSOCIAÇÃO SALMONELLA-SCHISTOSOMA MANSONI
}

\section{José Roberto Lambertucci1, Pérsio Godoy2, Eduardo Alves Bambirra2, Jayme Neves ${ }^{1}$, Washington L. Tafuri² e Virginia Hora Rios Leite ${ }^{2}$}

\begin{abstract}
Vinte pacientes com a associação Salmonella-S. mansoni (Grupo 1) e $20 \mathrm{com}$ esquistossomose mansoni hepatesplênica (Grupo 2) foram selecionados para o estudo. Submeteram-se os pacientes dos Grupos 1 e 2 a exame clínico minucioso e a uma série de exames complementares, com destaque para as provas de função renal. Em 10pacientes do Grupo 1 e 20 do Grupo 2, realizou-se, ainda, estudo histológico do rim à microscopia óptica, de fluorescência e eletrônica. As alterações renais foram mais freqüentes nos pacientes do Grupo 1. Após o tratamento dos pacientes do Grupo 1, com antibióticos e/ou esquistossomicidas, observou-se regressão das alterações renais sob o ponto de vista clínico, laboratorial e imunopatológico. Os autores concluem pela existência de duas nefropatias distintas: a nefropatia esquistossomótica e a encontrada em pacientes com a associação Salmonella-S. mansoni.
\end{abstract}

Palavras chaves: Esquistossomose. Associação Salmonella-S. mansoni. Glomerulonefrite. Lesão renal. Salmonelose.

Nos últimos 20 anos, vários estudos realizados em animais de laboratório e no homem estabeleceram a conexão entre esquistossomose mansoni e glomerulonefrite, particularmente na forma hepatesplênica da doença ${ }^{1} 11$ 17. De fato, estudos bem controlados têm incriminado a lesão renal na esquistossomose como secundária à deposição glomerular de imunocomplexos circulantes ${ }^{23} 28$. Por outro lado, na frebre tifóide alguns autores demonstraram a presença de lesão renal glomerular, com a deposição de antígeno de $S$. typhi no glomérulo e "glomerulite" durante a fase de estado da doença ${ }^{26} 27$.

Seria justo imaginar que nos casos de associação das duas doenças fosse também significativa a ocorrência de acometimento glomerular. Os primeiros relatos de alteração do sedimento urinário, denotando lesão glomerular grave, referem-se a casos de salmonelose crônica associada à esquistossomose por S. haematobium ${ }^{79}$. A seguir, surgiram outros registros na literatura confirmando as alterações renais na associação com o S. mansoni ${ }^{4} 10$.

A maioria dos trabalhos, até o momento, tem se restringido ao relato de casos de pacientes com alteraçōes urinárias graves ${ }^{14} \mathbf{2 0}$. Inexistem, entretanto, estudos prospectivos capazes de estabelecer a real

1. Núcleo de Estudos sobre Esquistossomose. Departamento de Clínica Médica. Faculdade de Medicina da Universidade Federal de Minas Gerais, 30000 Belo Horizonte, Minas Gerais, Brasil

2. Departamento de Anatomia Patológica e Medicina Legal da Faculdade de Medicina da Universidade Federal de Minas Gerais.

Trabalho financiado parcialmente pelo CNPq e FINEP.

Recebido para publicação em 23/7/86. importância clínico-epidemiológica e anátomo-patológica dessas alterações. Além disso, nos pacientes com a associação Salmonella-S. mansoni, ainda não se estabeleceu qual dos dois agentes é o responsável pela lesão renal.

O objetivo deste trabalho é relatar as alterações renais observadas, sob o ponto de vista clínico, laboratorial e imunopatológico, em 20 pacientes com a associação Salmonella-S. mansoni, comparando-as com as encontradas em 20 pacientes com esquistossomose mansoni hepatesplênica.

\section{MATERIAL E MÉTODOS}

\section{Origem e identificação dos pacientes}

No periodo de maio de 1977 a julho de 1983, 20 pacientes com a associação Salmonella-S. mansoni (Grupo 1) e 20 com esquistossomose hepatesplênica (Grupo 2) foram selecionados para este estudo.

Os pacientes do Grupo 1 encontravam-se na faixa etária de 5 a 28 anos (média: 17,1), sendo seis do sexo feminino e 14 do sexo masculino, nove pardos, nove brancos e dois pretos. O diagnóstico da associação Salmonella-S. mansoni era admitido quando se preenchiam os seguintes requisitos ${ }^{21}$ :

a) febre por período de três ou mais semanas de duração;

b) isolamento de Salmonella sp em pelo menos duas hemoculturas realizadas em momentos diferentes; c) identificação de ovos viáveis de $S$. mansoni nas fezes.

Os pacientes do Grupo 2 foram selecionados como controle, considerando-se que a associação 
Salmonella-S. mansoni ocorre, mais freqüentemente, em pacientes com a forma hepatesplênica da esquistossomose. Todos os 20 pacientes deste grupo foram operados de hipertensão porta em virtude de sangramento por varizes esofagianas. Eles situavam-se na faixa etária de 14 a 46 anos (média: 25,6 ), sendo seis do sexo feminino e 14 do sexo masculino, quatro pardos e 16 brancos.

\section{Exame clínico e subsidios complementares}

Os pacientes dos Grupos 1 e 2 submeteram-se a exame clínico completo antes do tratamento. Deu-se atenção especial à avaliação de queixas urinárias, à presença de edema e aos níveis de tensão arterial. Além disso, procurou-se excluir a vigência ou vestigios de outras doenças que pudessem influir na análise das alterações urinárias. Os seguintes exames foram feitos na maioria dos pacientes: a) hemograma, hemossedimentação, contagem de plaquetas, provas de função hepática (SGOT, SGPT, fosfatase alcalina, tempo de protrombina, proteinas totais e fracionadas), telerradiografia de tórax, glicemia de jejum; b) ASTO, fator antinúcleo, teste de látex, HBsAg, VDRL, Machado-Guerreiro, reação de Widal, eletroforese de hemoglobina; c) hemoculturas ${ }^{6}$, coproculturas e exame parasitológico de fezes.

\section{Exames utilizados para avaliação da função renal}

Rotina de urina-Foram realizados pelo menos três exames antes de qualquer tratamento na primeira urina emitida pela manhã. Considerava-se hematúria quando se observava mais de cinco hemácias por campo $(400 \mathrm{X})$ e piúria quando o número de piócitos era maior que cinco por campo ( $400 \mathrm{X})$. $O$ sedimento era realizado por um dos autores (JRL).

Outros exames - Uréia e creatinina no plasma, depuração de creatinina, proteinúria de 24 horas, urocultura e urografia excretora. As técnicas na realização destes exames já foram descritas anteriormente ${ }^{14}$.

\section{Obtenção dos fragmentos de rim para o estudo histológico}

Os fragmentos de rim foram obtidos por intermédio de biópsia renal ou à necrópsia. Os pacientes que se submeteram à biópsia renal foram esclarecidos a respeito do método e sobre os objetivos do trabalho; o exame só foi efetuado após sua permissão ou a de seus familiares. A biópsia renal foi realizada em oito pacientes do Grupo 1, através de punção percutânea ${ }^{19}$. Nos casos 3 e 5, os fragmentos de rim foram obtidos durante a necrópsia, 12 e 24 horas após o óbito. No
Grupo 2, 20 pacientes foram biopsiados durante o ato cirúrgico para tratamento de hipertensão porta.

\section{Estudos realizados nos fragmentos do tecido renal}

Os fragmentos retirados por biópsia foram divididos em três partes para estudo à microscopia óptica, de imunofluorescência e eletrônica.

a) microscopia óptica: o fragmento destinado à microscopia óptica foi imediatamente fixado em formol a $10 \%$, mantido no fixador por tempo mínimo de 24 horas, e, a seguir, processado para inclusão em parafina. Após secções de 3 a 4 micrômetros o material foi corado pela hematoxilina-eosina (HE), ácido periódido de Schiff(PAS) e prata metenamina (PASM). As lâminas foram examinadas em microscópio binocular Zeiss, por dois examinadores, sendo confontradas suas impressões diagnósticas. Em caso de discordância, os dois reexaminavam as lâminas em conjunto, conhecendo então os dados clínicos, até que fosse possivel obter o consenso.

b) microscopia de imunofluorescência: os fragmentos foram transportados em solução salina tamponada a $4^{\circ} \mathrm{C}$, incluidos em resina (Tissue-Teck Compound-OCT de Ames Co. USA) para cortes em congelação, e, em seguida, congelados a $-90^{\circ} \mathrm{C}$. Dos fragmentos congelados foram feitos cortes de 4 micrômetros de espessura em criótomo a $-20^{\circ} \mathrm{C}$. Foi usada a técnica de imunofluorescência direta com antiglobulina marcada com fluoresceína, de acordo com método descrito por Kaplan ${ }^{12}$. Utilizaram-se conjugados monoespecificos de globulina de coelho anti IgG, IgM, IgA e C3 humanos, marcados com isotiocianato de fluoresceina, na diluição de 1:20. Em cada sessão de leitura sempre foram utilizados rins humanos com reação imunofluorescente positiva e negativa como controle.

c) microscopia eletrônica: o terceiro fragmento foi fixado em aldeído glutárico a $3 \%, 0,1 \mathrm{M}$ em tampão fosfato, $\mathrm{pH} \mathrm{7,2}$ por três horas, lavado em sacarose $0,1 \mathrm{M}$, refixado em ósmio a $1 \%$, desidratado em álcoois, infiltrado em epon-acetona e incluidos em epon. Nos cortes semifinos, corados pelo azul de toluidina em bórax, foram isolados os glomérulos. Os cortes ultrafinos foram colhidos em porta objetos de cobre e corados com acetado de uranila e pelo Reynold's. A análise foi feita em fotografias obtidas em microscópio Zeiss, EM 9S2.

\section{Tratamento clínico dos pacientes dos Grupos 1 e 2}

Os pacientes com a associação SalmonellaS.mansoni foram divididos em três grupos, segundo o 
Lambertucci JR, Godoy P, Bambirra EA, Neves J, Tafuri WL, Leite VHR. Envolvimento renal na associação SalmonellaSchistosoma mansoni. Revista da Sociedade Brasileira de Medicina Tropical 20: 83-90, Abr-Jun, 1987.

tratamento instituido: a) no primeiro grupo estão oito pacientes (casos 2, 3, 5, 6, 12, 13, 19, 20) que foram tratados com o cloranfenicol ( $50 \mathrm{mg} / \mathrm{kg} / 20$ dias) e, a seguir, com a oxamniquine ( $15 \mathrm{a} 20 \mathrm{mg} / \mathrm{kg}$ de peso, dose única); b) as pacientes RFM (caso 14) e MAR (caso 16) foram tratadas apenas com o antibiótico e acompanhadas clinicamente por período variável (50 dias a três anos) após o tratamento. Esta conduta foi tomada nos dois casos com o objetivo de avaliar se o tratamento da salmonelose era suficiente para obter a regressão das alterações urinárias; c) os pacientes do terceiro grupo (casos 1, 4, 7, 8, 9, 10, 11, 15, 17, 18) foram tratados com a oxamniquine, sem o uso prévio de antibiótico ${ }^{16}$.

Os pacientes do Grupo 2 foram tratados com a oxamniquine, após a cirurgia para hipertensão porta.

\section{Controle pós-tratamento}

Após a alta hospitalar, o controle ambulatorial com 30 a 60 dias foi possivel em oito pacientes do Grupo 1. Em seis casos realizou-se controle pós-tratamento dentro do prazo de seis meses a três anos (casos 8, 12, 13, 14, 16 e 17). No Grupo 2, apenas um paciente foi controlado oito meses após a primeira internação. A biópsia renal foi repetida após o tratamento em três pacientes do Grupo 1. Os pacientes LJS (caso 13) e MAR (caso 16) submeteram-se à biópsia antes e seis meses após o tratamento. A paciente RFM (caso 14) submeteu-se à biópsia renal antes, 50 dias e 14 meses após a primeira internação. No Grupo 2 , nenhum paciente foi rebiopsiado.

\section{Análise estatística}

Utilizou-se o teste do qui-quadrado $\left(\mathrm{X}^{2}\right)$ com correção de Yates. Aceitou-se o nivel de significância de $5 \%$.

\section{RESULTADOS}

Queixas urinárias, edema, ascite e hipertensão arterial nos pacientes dos Grupos 1 e 2

Dos 20 pacientes do Grupo 1, 11 (55\%) apresentaram queixas urinárias à internação, enquanto no Grupo 2, apenas três (15\%) o fizeram. Esta diferença é estatisticamente significativa ao nível de $5 \%$. As queixas mais comuns, em ordem de importância, foram: urina escura, diminuição do volume urinário, hematúria, polaciúria, algúria, disúria e dor lombar.

Edema periférico foi identificado em nove pacientes (45\%) do Grupo $1 \mathrm{e}$ em três (15\%) do Grupo 2 e hipertensão arterial em um caso (5\%) de cada Grupo.

Todos os sintomas e sinais observados nos pacientes do Grupo 1 desapareceram após o tratamento com o cloranfenicol e/ou com a oxamniquine.

\section{Exames utilizados para avaliação da função renal}

As alterações identificadas no exame de urina, nos Grupos 1 e 2, estão especificadas na Tabela 1. Para todos os elementos a freqüència foi maior no Grupo 1. A urocultura realizada nos pacientes do Grupo 1 foi positiva para Salmonella sp em quatro

Tabela 1 - Alterações observadas no exame da urina em 20 pacientes com a associação Salmonella-S. mansoni e 20 com esquistossomose hepatesplênica

\begin{tabular}{|c|c|c|c|}
\hline \multirow{2}{*}{$\begin{array}{c}\text { Alteraçóes } \\
\text { no } \\
\text { Exame da urina }\end{array}$} & \multicolumn{2}{|c|}{ Número de pacientes $(\%)$} & \multirow{2}{*}{$\begin{array}{c}\text { Significância } \\
\text { estatística } \\
(5 \%)\end{array}$} \\
\hline & $\begin{array}{c}\text { Associação } \\
\text { Salmonella-S. mansoni } \\
(n=20)\end{array}$ & $\begin{array}{c}\text { Esquistossomose } \\
\text { hepatesplênica } \\
\quad(n=20)\end{array}$ & \\
\hline $\begin{array}{l}\text { Proteinúria } \\
\text { Hematúria } \\
\text { Piúria } \\
\text { Cilindros hemáticos } \\
\text { Outros cilindros* }\end{array}$ & $\begin{array}{r}14(80) \\
13(65) \\
14(70) \\
5(25) \\
15(75)\end{array}$ & $\begin{array}{l}7(35) \\
2(10) \\
1(5) \\
0(0) \\
6(30)\end{array}$ & $\begin{array}{l}S \\
S \\
S \\
- \\
S\end{array}$ \\
\hline $\begin{array}{l}\text { Total de pacientes } \\
\text { com alterações }\end{array}$ & $17(85)$ & $7(30)$ & $\mathbf{S}$ \\
\hline
\end{tabular}

$\mathrm{S}=$ Significativo

* = Cilindros hialinos e granulosos 
casos (20\%). No Grupo 2, a urocultura foi negativa em todos.

O número de pacientes dos Grupos 1 e 2, com valores anormais para uréia, creatinina, depuração de creatinina e proteinúria de 24 horas, está anotado na Tabela 2. Apenas um paciente no Grupo 1 e dois no Grupo 2 apresentaram proteinúria em níveis compatíveis com o diagnóstico de síndrome nefrótica.
Nos pacientes do Grupo 1, observou-se melhora evidente após o tratamento. Em oito casos, entretanto, examinados 30 dias após o tratamento, ainda foi possivel observar hematúria em quatro (50\%), proteinúria em um (13\%), piúria em um (13\%) e cilindrúria em um (13\%). De três pacientes examinados seis meses após o tratamento, apenas um mantinha hematúria. De cinco pacientes controlados, de nove meses a três anos

Tabela 2 - Alteração de algumas provas de função renal nos pacientes dos Grupos 1 e 2

\begin{tabular}{lll}
\hline Provas de & \multicolumn{2}{c}{ Número de pacientes com alterações (\%) } \\
\cline { 2 - 3 } função renal & Grupo 1 & Grupo 2 \\
\hline $\begin{array}{l}\text { Uréia } \\
\text { (maior que } 45 \mathrm{mg} / \mathrm{dl} \text { ) }\end{array}$ & $3(15)$ & $0(0)$ \\
$\begin{array}{l}\text { Creatinina } \\
\text { (maior que } 1,4 \mathrm{mg} / \mathrm{dl} \text { ) }\end{array}$ & $2(10)$ & $0(0)$ \\
$\begin{array}{l}\text { Depuração de creatinina } \\
\text { (menor que } 80 \mathrm{ml} / \mathrm{min} \text { ) }\end{array}$ & $3(21)$ & $2(18)$ \\
$\begin{array}{l}\text { Proteinúria } \\
\text { (maior que } 150 \mathrm{mg} / 24 \mathrm{~h} \text { ) }\end{array}$ & $11(55)$ & $7(35)$ \\
\hline
\end{tabular}

após o tratamento, nenhum apresentava alteração do sedimento urinário.

No Grupo 2, apenas um paciente foi reexaminado nove meses após a alta hospitalar. Este paciente, que exibia quadro clínico-laboratorial compatível com síndrome nefrótica na primeira internação, voltou para controle nove meses depois em anasarca, hipertenso e com várias alterações urinárias (proteinúria de 4,5 $\mathrm{g} / 24 \mathrm{~h}$, hematúria, cilindros graxos e cerosos).

\section{Alteraçôes glomerulares evidenciadas à microscopia óptica nos pacientes dos Grupos 1 e 2}

O exame histológico do rim, à microscopia óptica, foi possivel em nove dos 10 pacientes biopsiados no Grupo 1. Em todos os casos foram observadas alterações glomerulares. Em quatro (44\%) $(2,3,5$ e 12), o diagnóstico foi de glomerulopatia mesangioproliferativa; em três $(33 \%)(11,16$ e 19$)$ de proliferativa focal e em dois $(22 \%)(13$ e 14$)$ de proliferativa difusa endocapilar (Fig. 1).

No Grupo 2, o estudo à microscopia óptica foi possivel em todos os pacientes. Em 13 casos (65\%) o exame foi considerado normal; em dois $(10 \%)$, alterações histológicas mínimas; em dois $(10 \%)$, proliferativa focal; em um (5\%), glomerulopatia mesangioproliferativa e em outros dois (10\%), membranoproliferativa.

Nos pacientes com SSP foi freqüente o encontro, no interstício, de focos de infiltrado linfoplasmocitário com discreta fibrose e, às vezes, atrofía tubular. Esta nefrite intersticial foi, de maneira geral, mais intensa do que a observada nos pacientes com esquistossomose hepatesplênica, mas, ainda assim, apenas moderada.

Alteraçōes glomerulares evidenciadas à microscopia de fluorescência nos pacientes dos Grupos 1 e 2

O estudo, à microscopia de fluorescência, foi realizado em oito pacientes do Grupo 1 . Seis (75\%) exibiam fluorescência positiva antes do tratamento. Em quatro casos $(1,11,13$ e 19) a fluorescência foi positiva para $\operatorname{IgG}$ e $\mathrm{C}_{3}$; em três casos $(14,16$ e 19$)$ para $\mathrm{IgM} \mathrm{e} \mathrm{C}_{3}$ e em dois ( 2 e 12), a fluorescència foi negativa. Nenhum caso foi positivo para IgA. Observou-se, na fluorescência, aspecto granular fino e médio, difuso em todos os glomérulos, com distribuição no eixo mesangial e em alças capilares (Fig. 3).

No Grupo 2, o estudo à microscopia de fluorescência foi efetuado em 19 pacientes. Em 12 casos (63\%) a fluorescência foi negativa para todos os elementos pesquisados ( $\operatorname{IgG}, \operatorname{IgA}, \operatorname{IgM~e~} \mathrm{C}_{3}$ ). Em dois ( $11 \%)$, ela foi positiva para IgG; em sete ( $37 \%$ ), para IgM, em três ( $16 \%$ ), para IgA e em quatro ( $21 \%$ ), para $\mathrm{C}_{3}$. Nos casos positivos, a fluorescência apresentava aspecto semelhante ao encontrado no Grupo 1, mas de menor intensidade. 
Lambertucci JR, Godoy P, Bambirra EA, Neves J, Tafuri WL, Leite VHR. Envolvimento renal na associação SalmonellaSchistosoma mansoni. Revista da Sociedade Brasileira de Medicina Tropical 20: 83-90, Abr-Jun, 1987.

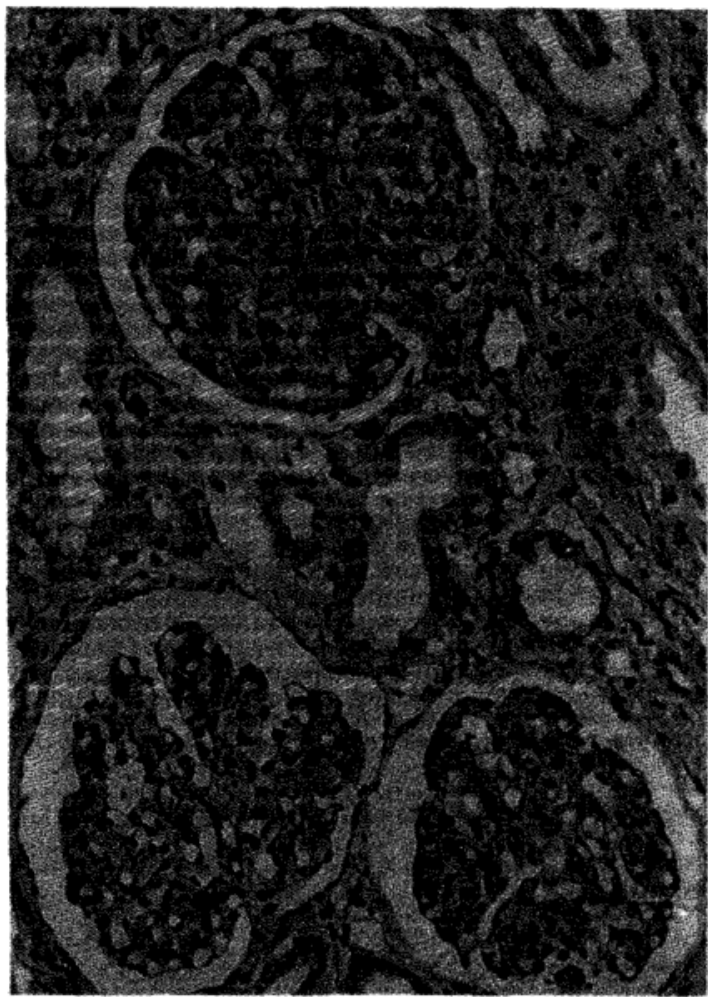

Fig. 1 - Associação Salmonella-S. mansoni (caso 14). Biópsia renal antes do tratamento. Glomerulopatia proliferativa difusa endocapilar. Glomérulos aumentados de volume difusamente, mostrando importante proliferação celular e oclusão ou redução da luz das alças capilares ( $H E-250 X)$.

Alterações glomerulares evidenciadas à microscopia eletrônica nos pacientes dos Grupos 1 e 2

No Grupo 1 , o estudo à microscopia eletrônica foi possivel, antes do tratamento, em quatro pacientes e repetido, após o tratamento, em três. No Grupo 2, o estudo à microscopia eletrônica, foi possivel em 16 pacientes.

Não foram identificadas alterações características capazes de diferenciar um grupo do outro. $\mathrm{Na}$ maioria dos casos as alterações foram discretas, mostrando-se mais pronunciadas nos pacientes do Grupo 1. As alterações mais freqüentemente encontradas foram: a) tumefação e vacuolização do citoplasma dos podócitos, com alargamento das cisternas do retículo endoplasmático granular. $\mathrm{O}$ mesmo se verifica em relação às células mesangiais e às células endoteliais; $b$ ) proliferação focal $e$, às vezes difusa, das células mesangiais, com ou sem aumento da matriz;c)

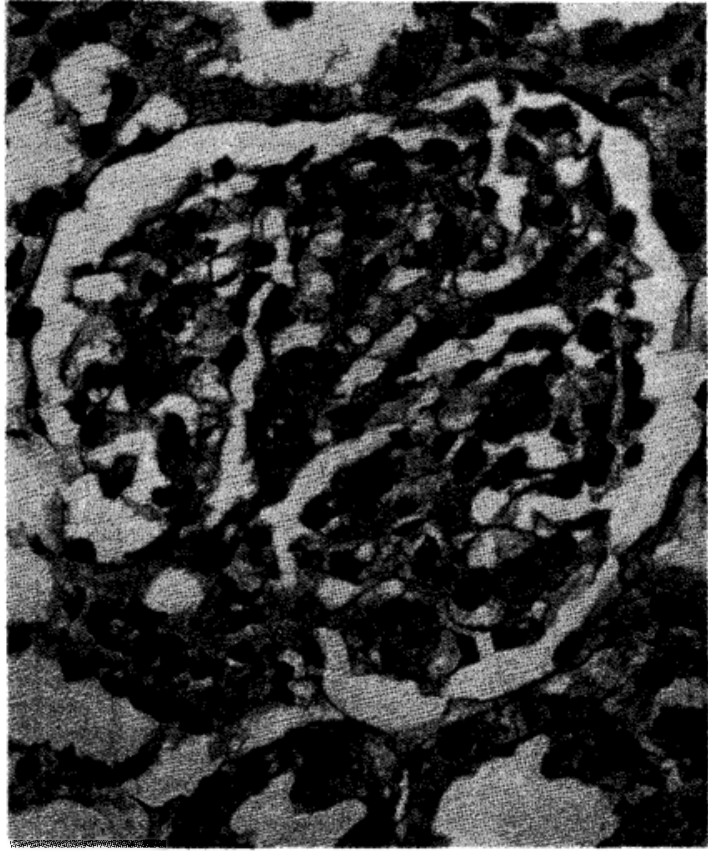

Fig. 2-Associação Salmonella-S. mansoni (caso 14). Biópsia renal 50 dias após o tratamento. Regressão da proliferação celular. Inúmeras alças capilares são patentes (HE-512X).

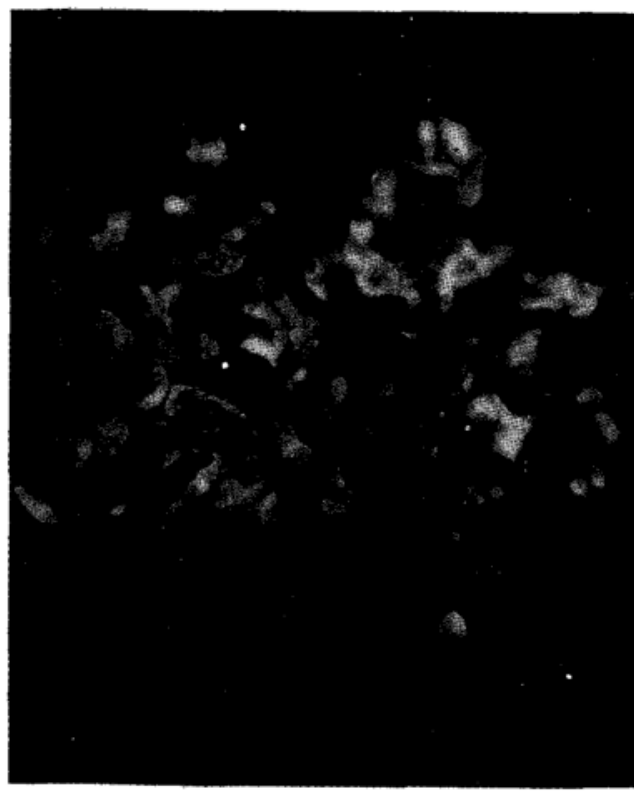

Fig. 3 - Associação Salmonella-S. mansoni (caso 19). Imunofluorescência positiva para IgG com padrão granular fino. Distribuição mesangial e nas paredes capilares, difusamente $(200 X)$. 
Lambertucci JR, Godoy P, Bambirra EA, Neves J, Tafuri WL, Leite VHR. Envolvimento renal na associação SalmonellaSchistosoma mansoni. Revista da Sociedade Brasileira de Medicina Tropical 20: 83-90, Abr-Jun, 1987.

coalescência ou fusão dos pés dos podócitos, em algumas áreas, com alterações evidentes das fendas de filtração; d) em geral, a membrana basal mostrou-se integra e bem homogênea em toda extensão da alça capilar. Em pelo menos um caso de cada grupo, tornou-se evidente o encontro de depósitos eletrondensos subendoteliais, junto da membrana basal e na espessura da mesma (Fig. 4).

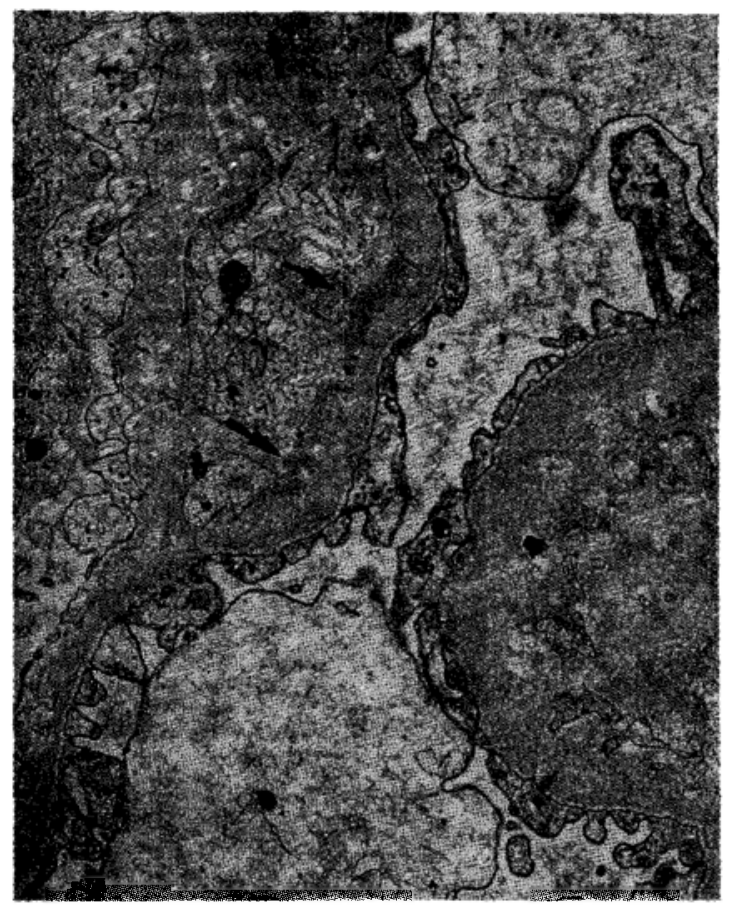

Fig. 4 -Associação Salmonella-S. mansoni (caso 19). Alça glomerular mostrando depósito eletrondenso subendotelial (setas) em faixa (4620X).

Evolução anatomopatológica (renal) pós-tratamento dos pacientes do Grupo 1

Nos très pacientes do Grupo 1, biopsiados após o tratamento, observou-se regressão progressiva das alterações identificadas à microscopia óptica na primeira biópsia; dois pacientes (casos 13 e 14) tinham o diagnóstico de glomerulopatia proliferativa difusa $\mathrm{e}$ outro (caso 16), de glomerulopatia proliferativa focal. Houve também negativação da fluorescência nas biópsias realizadas após o tratamento. $\mathrm{Na}$ microscopia eletrônica, mesmo notando-se melhora, foram ainda observadas alterações evidentes (proliferação celular, aumento da matriz, achatamento dos pés dos podócitos) meses após o tratamento. As alterações renais também regrediram nos pacientes (casos $14 \mathrm{e}$ 16) tratados com antibióticos (Fig. 2).

\section{DISCUSSÃO}

Excluindo os pacientes com infecção urinária, como interpretar as alterações renais (glomerulares) observadas nos pacientes com a associação Salmonella-S. mansoni? A etiopatogenia da lesão renal identificada nestes casos è a mesma encontrada em pacientes com esquistossomose hepatesplênica? A infecção bacteriana apenas agravaria lesões renais esquistossomóticas preestabelecidas?

Para os pacientes com a nefropatia esquistossomótica existe um perfil mais ou menos bem delineado 1351123 . A lesão renal ocorre mais freqüentemente na segunda e terceira décadas de vida; no sedimento urinário predomina o encontro de proteinúria e hematúria, sendo a síndrome nefrótica a forma de apresentação clínica mais comum; a doença é caracteristica de pacientes com a forma hepatesplênical ${ }^{18}$; é freqüente o encontro de complexos Ag-Ac circulantes, sendo o antigeno proveniente do verme adulto de $S$. mansoni; ocorre diminuição do complemento sérico; as lesões renais mais freqüentemente identificadas, à microscopia óptica, são a glomerulopatia membranoproliferativa e a esclerose focal; imunoglobulinas, complemento e antígenos do verme já foram identificados no glomérulo destes pacientes; e à microscopia eletrônica, estes achados correspondem a depósitos eletrondensos. A lesão renal, até o momento, não parece responder à terapêutica esquistossomicida ou imunossupressora.

Com base em nossos dados e também aproveitando informações recolhidas na literatura 247142025 , pode-se tentar fixar um perfil das alterações renais nos pacientes com a associação Salmonella-S. mansoni. Os pacientes se encontram mais freqüentemente situados nas duas primeiras décadas de vida. Talvez devido à presença do quadro toxêmico, as queixas urinárias não sejam valorizadas pelos pacientes e só são veiculadas após questionário dirigido; no sedimento urinário predominam os achados de proteinúria, hematúria, piúria e cilindrúria hemática; as imunoglobulinas séricas encontram-se muito elevadas e o complemento sérico C3 diminuido; também é freqüente o encontro de imunocomplexos circulantes; as lesões renais mais freqüentemente identificadas, à microscopia óptica, enquadram-se na glomerulopatia mesangioproliferativa, focal ou difusa; na imunofluorescência predominam os depósitos de IgG, IgM, e C3 no mesângio e em paredes capilares, de aspecto granular, que, à microscopia eletrônica, correspondem a depósitos eletrondensos. As alterações renais observadas sob o ponto de vista clínico, laboratorial e imunopatológico são reversíveis após tratamento com antibióti$\cos$ e/ou esquistossomicidas. 
Da exposição destes dois perfis ficam evidentes as semelhanças. As duas doenças apresentam caracteristicas comuns que as incluem no grupo das doenças por imunocomplexos. Algumas diferenças, entretanto, precisam ser enfatizadas.

A nefropatia esquistossomótica é caracteristica de pacientes com a forma hepatesplênica da doença ${ }^{124}$, não tendo ainda sido demonstrada em pacientes com esquistossomose hepatintestinal. Isto nāo parece ser necessariamente verdadeiro para os pacientes com a associação Salmonella-S. mansoni e lesão renal. Dois pacientes com salmonelose de curso prolongado (casos 13 e 14), neste trabalho, e com lesão renal evidente (glomerulopatia proliferativa difusa) apresentaram regressão completa da esplenomegalia após o tratamento da salmonelose. Um dos pacientes submetidos à autópsia (caso 3 ) também não apresentava esquistossomose hepatesplênica e era portador de lesão renal (glomerulopatia mesangioproliferativa).

Outro aspecto interessante a ser lembrado, diz respeito aos pacientes com esquistossomose hematóbica. A lesão renal na infecção humana pelo $S$. haematobium difere muito da produzida por outros esquistossomos, porque os vermes habitam primariamente o plexo vesical. Além disso, a lesão hepática geralmente é discreta. Alguns autores ${ }^{11} 24$, após estudos minuciosos, não evidenciaram lesão glomerular em pacientes com esquistossomose hematóbica. Por outro lado, pacientes com a associação Salmonella-S. haematobium desenvolvem lesāo renal e sindrome nefrótica ${ }^{8}$. Este é mais um argumento a favor da Salmonella como agente da lesão renal em pacientes com a associação Salmonella-S. mansoni.

A partir destes dados podemos responder a algumas indagações. A infecção bacteriana certamente pode agravar as lesões esquistossomóticas preestabelecidas. Pacientes com esquistossomose hepatesplênica e nefropatia esquistossomótica podem, na presença de infecção por Salmonella, apresentar piora do quadro renal. Esta é uma explicação possível para o achado de Carvalho Filho e cols. ${ }^{4}$, que encontraram lesões renais sugestivas de glomerulopatia esquistossomótica em pacientes com a associação Salmonella-S. mansoni. O mais importante, entretanto, é que estes dados permitem concluir que pacientes com esquistossomose hepatintestinal e infecção crônica por Salmonella também podem desenvolver lesão renal. Já era possivel prever o acerto desta afirmação baseando-se em dados de literatura. Sitprija e cols. ${ }^{26}$, por exemplo, demonstraram lesão renal em pacientes com febre tifóide (sem esquistossomose), ou ainda a relação já demonstrada em outros trabalhos entre septicemia crônica e lesão renal ${ }^{13} 22$. A doença renal em pacientes com a associação Salmonella-S. mansoni seria, então, uma doença por imunocomplexos, onde o antigeno é bacteriano. A presença de anticorpo antibactéria na circulação em pacientes com a associação já é do nosso conhecimento e, como exemplo, podemos citar as aglutininas pesquisadas na reação de Widal ${ }^{15}$. Na presença do antígeno (bactéria e seus produtos) e do anticorpo, é possivel esperar a formação de complexos circulantes. A diminuição do complemento sérico $\mathrm{C} 3$, o encontro de imunoglobulinas e complemento depositados no glomérulo e a presença de depósitos eletrondensos já foram demonstrados $^{14}$. Aí estão todos os ingredientes necessários para explicar uma doença renal por imunocomplexos com antígeno bacteriano.

Outra diferença evidente, com relação à lesão renal em pacientes com a associação Salmonella$S$. mansoni e na esquistossomose hepatesplênica, é a evolução clínica pós-tratamento. Nossos dados demonstram que a lesão renal nos pacientes com a associação são reversiveis após o tratamento clínico. Em pelo menos dois pacientes (casos 14 e 16) fica ainda demonstrado que o tratamento apenas com antibióticos também reverte a lesão renal. Mais uma vez estes são dados evidentes a favor da infecção bacteriana como agente, através de mecanismo imunológico, da lesão glomerular. A lesão renal, observada em pacientes com endocardite bacteriana, representa, sob vários aspectos, o modelo de nefropatia encontrada em pacientes com a associação Salmonella-S. mansoni $i^{1322}$.

Todos estes dados analisados em seu conjunto depõem a favor da existência de duas nefropatias distintas: a nefropatia encontrada em pacientes com a associação Salmonella-S. mansoni e a nefropatia esquistossomótica. Elas têm em comum o fato de serem doenças por imunocomplexos, mas diferem, com grande probabilidade, na origem e tipo do antígeno presente no imunocomplexo e no rim. Podem ainda, em alguns casos, representar o somatório das duas doenças. A presença de antígeno de Salmonella nos imunocomplexos circulantes e no rim e a eluição tecidual de anticorpo anti-Salmonella deverão confirmar esta hipótese.

\section{SUMMARY}

Twenty patients with Salmonella-Schistosoma mansoni associated infections (Group 1) and twenty with hepatosplenic schistosomiasis mansoni (Group 2) were selected for the present study. Patients in both groups underwent detailed clinical examination and a series of complementary examinations with an emphasis on renal function tests. In ten patients from Group 1 and in twenty from Group 2, histological examination of kidney biopsy material was also performed and examined 
under light, fluorescent and electron microscopy. Renal alterations were more frequent in patients from Group 1. After antibiotic and/or schistosomicide treatment in patients from Group 1 remission of the renal lesions occurred as measured by clinical, laboratory and immunopathological observations. The authors conclude that two distinct nephropathies exist: schistosomal nephropathy and that found in patients with the Salmonella-S. mansoni association.

Key-words: Schistosomiasis. SalmonellaS. mansoni association. Glomerulonephritis. Renal lesion. Salmonellosis.

\section{REFERÊNCIAS BIBLIOGRÁFICAS}

1. Andrade ZA, Rocha H. Schistosomal glomerulopathy. Kidney International 16:23-29, 1979.

2. Bassily S, Farid Z, Barsoum RS, Soliman LA, Higashi GI, Miner WF. Renal biopsy in Schistosoma - Salmonella associated nephrotic syndrome. Journal of Tropical Medicine and Hygiene 79:256-258, 1976.

3. Carvalho EM, Andrews BS, Martinelli R, Dutra M, Rocha $\mathrm{H}$. Circulating immune complexes and rheumatoid factor in schistosomiasis and visceral leishmaniasis. American Joumal of Tropical Medicine and Hygiene 32: 61-68, 1983.

4. Carvalho Filho E, Brito E, Gusmão E, Teixeira RS, Rocha H. Envolvimento renal na salmonelose septicêmica prolongada. Revista da Sociedade Brasileira de Medicina Tropical 11: 175-180, 1977.

5. Dutra M, Carvalho Filho EM, Gusmão EA, Queiroz FP, Brito E, Rocha H. Tratamento da glomerulopatia da esquistossomose mansônica: efeito de corticosteróides, ciclofosfamida e esquistossomicidas. Revista do Instituto de Medicina Tropical de São Paulo 21:99-105, 1979.

6. Edwards PR, Ewing WH. The genus Salmonella. In: Identification of enterobacteriaceae. 3rd edition, Burgess Publishing, Minneapolis, p. 146-207, 1972.

7. Farid Z, Higashi GI, Bassily S, Miner WF. Immunecomplex disease in typhoid and paratyphoid fevers. Annals of Internal Medicine 85: 432, 1975.

8. Farid Z, Higashi G, Bassily S, Young SW, Sparks H. Chronic salmonellosis, urinary schistosomiasis and massive proteinuria. American Journal of Tropical Medicine and Hygiene 21: 578-581, 1972.

9. Hathout SE, El-Ghaffar YAE, Awny RY. Salmonellosis complicating schistosomiasis in Egypt. American Journal of Tropical Medicine and Hygiene 16: 462-472, 1967.

10. Higashi GI, Farid Z, Bassily S, Miner WF. Nephrotic syndrome in schistosomiasis mansoni complicated by chronic salmonellosis. American Journal of Tropical Medicine and Hygiene 24: 713-714, 1975.

11. Houba V. Experimental renal disease due to schistosomiasis. Kidney International 16: 30-43, 1979.

12. Kaplan MH. Immunologic studies of heart tissue. I. Production in rabbits of antibodies reactive with an autologous myocardial antigen following immunization with heterologous heart tissue. Journal of Immunology 80: 254-257, 1958.
13. Kim Y, Michael A. Chronic bacteremia and nephritis. Annual Review of Medicine 29: 319-325, 1978.

14. Lambertucci JR. Contribuição ao estudo das alterações renais na salmonelose septicêmica prolongada. Tese de doutorado, Universidade Federal de Minas Gerais, Belo Horizonte, 1984.

15. Lambertucci JR, Marinho RP, Ferreira MD, Neves J. The value of the Widal test in the diagnosis of prolonged septicemic salmonellosis. Revista do Instituto de Medicina Tropical de São Paulo 27: 82-85, 1985.

16. Lambertucci JR, Marinho RP, Ferreira MD, Neves J, Pedroso ERP. Eficácia terapêutica da oxamniquine oral em pacientes com salmonelose septicêmica prolongada. Revista do Instituto de Medicina Tropical de São Paulo 27: 33-39, 1985.

17. Lopez M. Aspectos renais da sindrome hepatoesplênica da esquistossomose mansoni. Tese de doutorado, Faculdade de Medicina da Universidade de Minas Gerais, Belo Horizonte, 1964.

18. Machado E. Proteinúria na esquistossomose mansônica hepatesplênica (Estudo eletroforético da urina e do soro sanguíneo). Tese. Faculdade de Medicina da Universidade de Pernambuco, Recife, 1965.

19. Miranda D, Paolucci AA. Biópsia renal. In: Paolucci AA. Nefrologia. (2: ed.) Guanabara Koogan, Rio de Janeiro, p. 55-61, 1982.

20. Musa AM, Saleh SY, Abuasha H. Transient nephritis during typhoid fever in five Sudanese patients. Annals of Tropical Medicine and Parasitology 75: 181-184, 1981.

21. Neves J, Lambertucci JR. Salmonelose septicêmica - prolongada. In: Neves J. ed. Diagnóstico e tratamento das doenças infectuosas e parasitárias. (2: ed.) Guanabara Koogan, Rio de Janeiro, p. 580-591, 1983.

22. Perez GO, Rothield N,Williams RC. Immune-complex nephritis in bacterial endocarditis. Archives of Internal Medicine 136: 334-336, 1976.

23. Rocha H. Glomerulopatia da esquistossomose mansônica. In: Universidade Federal da Bahia. Centro de Estudos de Doenças Regionais - CEDRE. Aspectos peculiares da infecção por $S$. mansoni. Centro Editorial e Didático da Universidade Federal da Bahia, Salvador, cap. 6, p. 133-160, 1984.

24. Sadigursky M, Andrade ZA, Danner R, Cheever AW, Kamel IA, Elwi AM. Absence of schistosomal glomerulopathy in Schistosoma haematobium infection in man. Transactions of the Royal Society of Tropical Medicine and Hygiene 70: 322-323, 1976.

25. Salih SY, Abu Subaa H, Abuasha H, Satir AA. Salmonellosis complicating schistosomiasis in the Sudan. Journal of Tropical Medicine and Hygiene 80: 14-18, 1977.

26. Sitprija V, Pipatanagul V, Boonpupknavig V, Boonpupknavig S. Glomerulitis in typhoid fever. Annals of Internal Medicine 81: 210-213, 1974.

27. Teixeira R. Salmoneloses prolongadas. In: Veronesi $\mathrm{R}(\mathrm{ed})$. Doenças Infecciosas e Parasitárias, 6a Edição, Editora Guanabara Koogan S.A., Rio de Janeiro, 400405, 1976.

28. Van Marck EAE. The glomerulopathy associated with Schistosoma mansoni infection; an experimental study in the mouse. Acta Leidensia 50: 1-123, 1983. 